\title{
Building the silver jubilee of Acta Botanica Brasilica
}

I remember that between 1991 and 1993, when I was special assistant to the President of the Botanical Society of Brazil (SBB), Dr. Eliana Nogueira, I participated actively in various SBB Board of Directors activities, in particular those involving Acta Botanica Brasilica (ABB). At that time, the journal was published twice a year and its contents were directed especially to phanerogam taxonomy, anatomy, morphology, and the publication of abstracts of theses and dissertations from Brazilian universities.

After careful assessment of the situation of the journal and difficulties faced by its editors, the SBB Board asked the Editorial Committee for a study outlining a new editorial policy for $A B B$, which would be implemented in the forthcoming volume. After several meetings with $A B B$ representatives, from 22 to 24 August 1993 in Brasilia, I coordinated a joint meeting of all members of the Editorial Committee of $A B B$ and $\mathrm{SBB}$ which resulted in the final draft of more comprehensive rules which extended journal scope and intended to encourage publication of research in different areas of Botany, thus changing the profile of the journal. This document included detailed instructions for the publication of papers in Portuguese and English or Spanish, as well as streamlining the evaluation process, speeding the process of publication of a manuscript.

With the publication of each volume, Brazilian researchers began to regard $A B B$ as another option for the publication of their scientific data, especially when journal frequency was changed in 1998 to three times a year and finally to quarterly in 2002, which provided a significant reduction in waiting time for authors to see their papers published.
The editorial policy is dynamic. It must be constantly reviewed and improved to meet the constant demand of the scientific community. Throughout these 25 years it has undergone several changes not only in presentation, but especially in content reflecting a clear commitment of the SBB and all those actively involved in the editorial process, beginning with publication regularity, now streamlined by using online submission and editing of manuscripts. However, besides the frequency of the journal, it should be noted that the increasing demands of indexers, funding agencies and evaluators of Brazilian journals, aimed at improving the quality of publications in the country, have become valuable tools for $A B B$ in its constant search for excellence.

A journal that has gone through all these transformations and reached the level where it is today deserves our compliments. The way $A B B$ grew reflects the increase of scientific production by Brazilian researchers from different fields of botanical knowledge, with ever more compelling works, contributing significantly to the growth of publication quality of those who focus on Scientia Amabilis in their research in Brazil.

It is a honor for me to congratulate SBB for its achievements, and wish success in future endeavors always aimed at improving scientifically Acta Botanica Brasilica.

Therezinha Sant'Anna Melhem Scientific Researcher (retired), Instituto de Botânica

(São Paulo, SP). 